\title{
REPENSAR \\ LA UNIVERSIDAD
}

Javier Meza*

El arte y el pensamiento constituyen las actividades más elevadas del hombre. Son las finalidades de la vida, y la sociedad debe organizarse de tal modo que los promueva en primer término. Una sociedad da señales de ser retrógrada cuando, en una crisis financiera, lo primero en que piensa es en cerrar los museos de arte y reducir el presupuesto de educación. Una civilización sin arte y sin pensamiento, o que no los valore, no es una civilización, sino un rebaño.

Robert Hutchins

No se ha mencionado la globalización del mundo bajo una misma racionalidad económica y tecnológica, de signo destructivo frente a la naturaleza $y$ de signo uniformador de las formas de vida, que ha elevado la razón ilustrada a un sistema de expolio integral de continentes enteros.

Eduardo Subirats

\section{Aproximaciones a un proyecto educativo}

\section{A un lado del Canal de Cuemanco} se encuentra la Universidad Autónoma Metropolitana-Xochimilco. Allí, flanqueados por agua podrida y nubes de moscos se levantan sus aplastantes edificios grises. Recientemente tanto el fétido olor del líquido estancado como los insectos han cedido un poco debido a que

* UAM-X, Departamento de Política y Cultura. 


\section{JAVIER MEZA}

las autoridades gubernamentales empezaron a cuidar los canales. Hecho que lo debemos agradecer al negocio de la concentración urbana, y no al respeto e interés que una institución educativa debiera provocar. $\mathrm{Al}$ comparar los sistemas educativos calificados despectivamente por las modas pedagógicas como 'tradicionales', con las propuestas educativas de la UAM-X, éstas resultan interesantes y prometedoras. Básicamente, según el llamado Documento Xochimilco, la Universidad Metropolitana fue creada para responder a los siguientes problemas: satisfacer la creciente demanda de alumnos por cursar estudios profesionales, permitirles ser agentes activos en los procesos de transformación social y responder a la oferta de trabajo con un profesionista de alta formación obtenido gracias a un cambio cualitativo del personal formador. Desde esta perspectiva el proyecto educativo de la Unidad Xochimilco surgió al proponer una "revisión profunda de las relaciones entre las ciencias y sus efectos, fundamentalmente la aplicación y la enseñanza, y un enfoque novedoso en la metodología educacional, en que el estudiante es el artífice de su propia formación". . $^{\prime}$

Según el proyecto, sólo el sistema modular podía servir para crear una universidad vinculada estrechamente con la sociedad y preocupada por revalorar novedosamente "la forma y modo de producción de conocimientos, y el papel del profesionista dentro de la sociedad". La enseñanza modular superaría a la enseñanza por disciplinas porque consiste en "unidades basadas en un objeto e interrogante sobre el mismo, donde se conjugan diversas ciencias y técnicas para dar respuestas científicas". Además, como pilar fundamental de esta acción crítica y creativa se proponía la investigación interdisciplinaria. ${ }^{2}$ Mientras que en la univer-

${ }^{1}$ Véase de Ramón Villarreal, y otros, Proyecto Xochimilco, 5 de junio de 1974, p. IV-V.

${ }^{2}$ Ramón Villarreal, en una carta enviada el 5 de junio de 1974 al entonces Rector General, Pedro Ramírez Vázquez, con base en Michaud, definía a la interdisciplinaridad, como la práctica que "es básicamente una perspectiva mental que combina curiosidad con receptividad y un espíritu de aventura y descubrimiento, incluye también la intuición de que existen relaciones entre todas las cosas que escapan a la observación corriente", $i b i d$. 
sidad tradicional la enseñanza, la ciencia y la aplicación de los conocimientos normalmente están desvinculados. Aquí, ahora se trataba de integrarlos creando un profesor-investigador perteneciente a una nueva universidad crítica y actuante preocupada también por formar un tipo de "estudiante que oriente su propia formación al intervenir en el proceso de la transformación de la realidad" cuyas condiciones de enseñanza-aprendizaje le permitiesen, ni más ni menos, romper con las 'concepciones precientíficas' y adquirir 'las científicas'.

Al inicio, siguiendo un criterio interdisciplinario se propuso la creación de dos divisiones (Ciencias Sociales y Humanidades, y Ciencias Biológicas y de la Salud) organizadas en departamentos, y un Tronco Común como

un mecanismo que permita capacitar al estudiante para el correcto manejo de las ideas, de las relaciones humanas, y de las cosas y le proporcione elementos de juicio para entender no sólo su profesión, sino también con un enfoque transdisciplinario, el ámbito total en que ésta es ejercida y que le permita enfrentarse a la multiplicidad y a la complejidad creciente de problemas que caracterizan el ámbito de su actividad futura. ${ }^{3}$

${ }^{3}$ Op. cit., p. iv. La idea del Tronco Común responde a la exigencia de que todo especialista debe poseer una 'cultura orgánica general'. Es decir, una cultura general que le impida aislarse de otros conocimientos, y por consiguiente sus puntos de vista no sólo sean unilaterales. Por eso se considera que: "La conciliación armónica entre especialización y sistema universal de los conocimientos debe ser uno de los oficios esenciales de la Universidad a fin de que se convierta en creadora fecunda de cultura", Rodolfo Mondolfo, Universidad: pasado y presente, 1966, Buenos Aires, EUDEBA, p. 73. En contra de esta importantísima idea en ocasiones se alzan las voces de la ignorancia pidiendo acabarla, quizá porque por limitaciones personales les resulta imposible intentar una comprensión global de la cultura. Por eso, conciben el Tronco como un lugar de castigo a donde se deben mandar a los peores profesores, cuando en términos lógicos debería ser al revés. Afortunadamente, existen excelentes profesores que no lo ven así y valoran perfectamente la trascendencia de dichos lugares. 
JAVIER MEZA

Sin duda, como siempre ocurre, el proyecto desbordaba optimismo.

No obstante, ya desde el primer módulo introductorio al proyecto (Tronco Interdivisional que cursan todos los alumnos) la buena intención de romper con las 'concepciones precientíficas' y adquirir 'las científicas' resulta jactanciosa y desmedida. Máxime porque para lograrlo es necesario aprender algunos planteamientos neopositivistas empapados de posiciones cientistas. Al grado de que, por ejemplo, en 1981 se reconoció que el Documento Xochimilco en sus planteamientos básicos contenía algunas contradicciones causadas por mezclar ideas pedagógicas, teoría del conocimiento y materialismo histórico, "resultado de una alianza de intereses y de grupos a los que representa". ${ }^{4}$ La exageración también se hizo presente al reflexionar acerca de la importancia y trascendencia de la enseñanza modular. Un autor, por ejemplo, confrontando la enseñanza modular con la enseñanza llamada tradicional encontraba que en esta última -inspirado sin duda en Paulo Freire y su definición de 'educación bancaria'- el alumno sólo era un receptor pasivo que recibía un conocimiento 'monopolizado por el maestro'. Pero, además, afirmaba tajantemente:

En la enseñanza tradicional la realidad nunca está presente. Ésta sólo es referida a través de categorías conceptuales, de palabras y juicios normativos, a través de una sucesión de experiencias cuidadosamente guiadas y asépticas que la ocultan, la tornan cada vez más difusa y la distorsionan. ${ }^{5}$

Según esto, la enseñanza tradicional nunca plantearía un problema invitando al alumno a resolverlo. Dichas así las cosas, uno no podía más que preguntarse si el ser humano sólo aprendió a conocer la rea-

${ }^{4}$ 1er. congreso sobre las bases conceptuales de la Universidad Autónoma Metropolitana Xochimilco, 1981, México, t. I., p. 35, UAM-X, s/f.

${ }^{5}$ Véase, Gustavo Rojas Bravo, El módulo: estructura teórica metodológica, Centro de Investigaciones Educativas. Seminario de Integración Metodológica, UAM-X, octubre de 1974, p. 3. 
REPENSAR LA UNIVERSIDAD

lidad y a resolver los problemas que ella le plantea hasta que conoció la enseñanza modular. Más adelante volveremos sobre esto.

Pero no solamente algo de lo anterior resultó preocupante. Desde finales de los años sesenta en la mayoría de los centros de enseñanza superior, el marxismo, con todas sus variantes, arreglos y acomodos, se fue convirtiendo no nada más en una parte de un conocimiento general obligatorio como debió haber sido. Para los años setenta era predominantemente el único enfoque válido y científico. Esta 'ciencia de las ciencias' (tal y como rezaba con gaya ignorancia supina un librillo de cuyo título no vale la pena acordarse) fue adoptada sobre todo por las disciplinas humanísticas, político-sociales, y económicoadministrativas. No obstante, no faltaron físicos, agrónomos, arquitectos, químicos y médicos obligados a leer por lo menos, cuando mejor les iba, La dialéctica de la naturaleza de Federico Engels. ${ }^{6}$ Pero, lo más terrible del asunto vino dado no sólo por querer reducir y tratar de explicar todos los problemas económicos, políticos y sociales utilizando la misma teoría, sino también porque, olvidando la exigencia científica de aprender en la fuente primaria, normalmente se pretendió aprender la 'ciencia de la ciencias' recurriendo a espantosos recetarios

${ }^{6}$ Sin duda, esta moda fue mundial, y forma parte de una historia que todavía está por escribirse analíticamente. Quizá, entre otras cosas, respondió a la mezcla de deseos de absoluto, y a las ansias de libertad y dominio que poseemos (el siglo XIX europeo constituyó un claro ejemplo de ello). Asimismo, no hay que olvidar que una importante vertiente del pensamiento occidental considera que: 1) para todas las preguntas sólo existe una respuesta correcta, y por lo tanto todas las demás se equivocan, 2) es posible encontrar un método para encontrar todas las respuestas correctas, y 3) todas las respuestas correctas son compatibles entre sí. Ver de Isaiah Berlin, "Decadencia de las ideas utópicas en Occidente", Vuelta, n 112, México, marzo de 1986, p. 17-27. Por eso Theodor W. Adorno recomendaba: "Hay que renunciar a la ilusión de que la esencia pueda ser constreñida a entrar en la finitud de las determinaciones filosóficas", o bien, "el conocimiento no se asimila hasta el fondo ninguno de sus objetos. No debe elaborar el fantasma de una totalidad". 


\section{JAVIER MEZA}

o manuales de divulgación esquemáticos y doctrinarios. Una vez aprendido el vulgar esquema, éste se aplicaba mecánicamente trasladándolo a cualquier problema sin importar el contexto, y si la realidad no se ajustaba a él era peor para la realidad. Y en efecto, fue peor pero para la realidad de nuestras instituciones educativas. Un vulgar maniqueísmo fatalista, disfrazado de ciencia, se introdujo en nuestra enseñanza condenando las complejas realidades a ser explicadas grotescamente, $\mathrm{y}$ a prometer un futuro promisorio que inexorablemente, como acto de fe, tenía que llegar. ${ }^{7}$ La UAM-X, a pesar de sus sanos y loables esfuerzos por transformar la enseñanza, no pudo escapar en muchos sentidos a lo anterior simplemente porque era imposible.

\section{Las dos funciones del saber}

El filósofo Janto, amo de Esopo, en una ocasión le pidió a éste servir dos banquetes: uno con el alimento más exquisito y otro con el más repudiable. Respondiendo a su deseo, el brillante esclavo sirvió a los invitados en las dos ocasiones lengua en todas las variedades: sopa, salsa, puré, asada, guisada, al grado de que todos decían que tenían ya la lengua escaldada de tanto comer lengua. Janto, contrariado, llamó al esclavo para castigarlo, pero Esopo inteligentemente le hizo ver cómo gracias a la lengua las sociedades producían artes, leyes, ciencias, etcétera, aunque también guerras, calumnias, injusticias. Por lo tanto, era el manjar más exquisito pero también el más repudiable y, por supuesto, tenía razón. Para Hegel, todo saber era un poder, pero olvidó

${ }^{7}$ Hablo desde mi experiencia. En alguna ocasión un grupo me confió que en la UAM-X tanto en el Tronco Interdivisional, como en el Tronco Divisional de Sociales una de las preocupaciones del alumno consistía en averiguar inmediatamente cuál de los teóricos marxistas era el preferido por el profesor. Descubriéndolo, era suficiente hablar bien de él para obtener una buena calificación. Después de todo la galería era interminable: Marx, Engels, Kautski, Lenin, Trozski, Stalin, Mao, Gramsci, Althusser, Poulantzas, pero casi siempre, Nikitin, Harnekcer, Makarenko, Afanasiev, etc. 
decir cómo éste puede servir tanto para liberar como para oprimir. Desde el surgimiento de los Estados modernos las universidades, como creadoras y conservadoras de la cultura y la ciencia, se han encontrado sometidas a dos tipos de funciones. Para los aparatos gubernamentales y empresas privadas han servido para producir tanto los cuadros o funcionarios necesarios para la burocracia estatal moderna al servicio del mantenimiento y funcionamiento del status quo, como trabajadores calificados. Pero también han sido espacios en donde se conservan y forjan las ideas que pueden servir para fortalecer a las sociedades civiles en contra de las prepotencias y pretensiones siempre desmedidas de las élites gobernantes.

Si bien es cierto que las universidades públicas son pagadas por los gobiernos, también es cierto que los gobiernos solamente son, o por lo menos deberían ser, los administradores (no siempre honrados) de la riqueza pública generada por la sociedad civil. Y es por eso que inevitablemente en toda universidad sana se generan saberes encontrados que sirven para liberar u oprimir al objetivo fundamental de todo espacio moderno preservador y productor de cultura y ciencia: la sociedad civil.

México siempre ha sido uno de los países más injustos del mundo tanto en el nivel material como en el espiritual. A nuestras burguesías les ha preocupado más el acrecentamiento de la riqueza que cualquier tipo de cultura. Por lo mismo, ésta casi siempre ha tenido que ser impulsada por nuestros gobiernos, pero indudablemente a niveles muy mediocres. No es casual que nuestro país sea eminentemente racista, al grado de que en él podemos encontrar no solamente ciudadanos de primera o segunda clase, sino incluso de tercera. ${ }^{8}$ La educación impulsada por nuestros ministros hasta ahora, salvo honrosas excepciones, casi siempre ha buscado más someter al individuo al consenso de las élites que promover en él una liberación social basada en un desarrollo

${ }^{8}$ Una nación que pretende ser justa, moderna e ilustrada para que realmente lo sea no puede tener a millones de seres sin nada en la cabeza y sumidos en condiciones infrahumanas como ocurre en México. 
JAVIER MEZA

integral. No en balde uno de los principales problemas de las universidades mexicanas consiste en que muchos de nuestros intelectuales siempre las han visto como un trampolín para ascender a las jerarquías gubernamentales. Dentro de las diferentes carreras que los centros educativos ofrecen, sobre todo los públicos, implícitamente se encuentra presente la carrera de 'científicos en burocracia'. Normalmente es 'cursada' por todos los profesores preocupados más por el ascenso social que por la enseñanza y el conocimiento, y que sin mucho esfuerzo les permite ir escalando los principales puestos administrativos universitarios hasta llegar a los ambicionados puestos públicos. Para este 'sacerdocio comprado' la universidad en sí no es un fin, sino más bien un simple medio. Precisamente muchas de las rebeliones estudiantiles de los años sesenta, además de las causas económicas, políticas y sociales, cuestionaron y rechazaron a las entonces calificadas 'universidades fábricas' porque en ellas, según el recalcitrante juicio, sobre todo se producían "los perros guardianes de las estructuras sociales vigentes". En el caso de México, lo anterior era cierto. A varias décadas de la revolución de 1910-1920 las demandas y necesidades sociales, económicas y políticas básicas de la mayoría de la población seguían sin cumplirse (tal y como ocurre hasta el día de hoy), y el acceso a las universidades era sobre todo para un pequeño grupo de privilegiados. ${ }^{9}$

La anterior situación explica, en parte, la adopción de los discursos marxistas en nuestros centros educativos a partir de esos momentos, a pesar de que dichos discursos desde hacía muchos años se habían "convertido en un sistema de legitimación trascendental de una burocracia totalitaria". ${ }^{10}$ Esto es, mientras que en otros lugares dichos discursos servían para oprimir, aquí se vieron como esperanza liberadora. Quizá el dogmatismo, la intolerancia y el simplismo con que fueron acogidos

${ }^{9}$ La mayoría de los movimientos sociales armados de los países del Tercer Mundo durante los años sesenta sólo se explican por las terribles condiciones de miseria existentes, las cuales hasta la propia Iglesia Católica denunció. Unas cuantas décadas después el cuadro parece repetirse pero a niveles más espantosos.

${ }^{10}$ Eduardo Subirats, Los malos días pasarán, 1992, Caracas, Angria, p. 12. 
explica en parte su fracaso, pero tampoco se debe olvidar la baja calidad de muchos de ellos. Asimismo, hay que tomar en cuenta otro factor muy importante: el poder para controlar normalmente reprime, pero en ocasiones más bien aprueba, autoriza. La fuerza del sistema político mexicano radica precisamente en su sabiduría para aplicar la vieja fórmula del gatopardismo 'cambiar para permanecer', unida a la capacidad para absorber y mediatizar todo discurso que se le opone. Y máxime cuando éste, a fuerza de repetirse sin originalidad y creatividad alternativa, se desgasta en fórmulas ridículas hasta vaciarse totalmente de contenido y sentido. Según nos dice Octavio Paz:

En el libro XII de los Anales, Tzu-Lu pregunta a Confucio: "Si el Duque de Wei te llamase para administrar su país, ¿cuál sería tu primera medida? El Maestro dijo: La reforma del lenguaje." No sabemos en dónde empieza el mal, si en las palabras o en las cosas, pero cuando las palabras se corrompen y los significados se vuelven inciertos, el sentido de nuestros actos y de nuestras obras también es inseguro. ${ }^{11}$

En un país con una grave anomia y, como consecuencia, prolífico 65 en pícaros y pinochos, es muy fácil corromper el sentido de las palabras. Así, por ejemplo, la oclocracia se convierte en democracia, la compra de conciencias en solidaridad, la vulgar psicología conductista inspirada en manipular ratas y aplicada a la producción en creatividad, el manejo de la opinión pública imitando a Goebbels en 'mucha política moderna', el saqueo de la nación en justicia, y la ignorancia se eleva al rango de virtud. ${ }^{12}$

11 Octavio Paz, El arco y la lira, 1972, México, FCE, p. 29.

${ }^{12}$ En nuestro país los mejores ejemplos para educar a la sociedad lo constituyen Guzmán de Alfarache y en general toda la novela picaresca, los delirantes seniles al borde de la muerte aferrados como sanguijuelas al poder, los borricos filósofos de nuestra cultura televisiva, y nuestros pésimos cómicos enseñándonos a mal reír por medio de un lenguaje destrozado y con un doble sentido que rebela el miedo a decir directamente las cosas a causa 
JAVIER MEZA

\section{Modelo y deseo}

Retornando a la UAM-X, durante los primeros años de aplicación del nuevo modelo educativo fueron muy importantes la voluntad y la esperanza. Sin duda, el optimismo desbordado y el deseo de hacer las cosas a la larga habrían ayudado a superar los humanos errores. La experiencia indica que el ensayo y el error es la mejor solución contra la amenaza del estancamiento. Pero una universidad no es una isla aun cuando sea autónoma. La alegría y el despilfarro que había traido consigo el boom petrolero del sexenio gubernamental 77-82 al poco tiempo se esfumó dejando paso a nubarrones que anunciaban tormentas. Pero fue necesario que transcurriera una década para que se reconocieran en América Latina los devastadores estragos provocados por economías detenidas bruscamente en su crecimiento. ${ }^{13}$ Para algunos sociólogos América Latina en general en esos momentos empezó a sufrir las patéticas consecuencias de un doble desorden provocado primero por

de una vieja educación que nunca toleró al pensamiento independiente. El ejemplo de la obediencia ciega y la genuflexión permanente de la mayoría de nuestros políticos ante el poder y el becerro de oro posiblemente tiene sus raíces en las costumbres monárquico-católicas de callar y obedecer.

${ }^{13}$ Según la Comisión Económica para América Latina (CEPAL), durante la década de los ochenta sólo el 5 por ciento de la población latinoamericana aumentó sus ingresos, mientras que el 75 por ciento los redujo. En 1970 la población que sobrevivía en extrema pobreza era de aproximadamente 136 millones; al finalizar los ochenta ésta era de 183 millones, de los cuales 90 millones se distribuían en Brasil y México. La CEPAL, analizando "la distribución del ingreso per capita de los hogares" $\mathrm{y}$ "los ingresos por trabajo relacionados con distintos tipos de ocupaciones de la estructura productiva o con distintos niveles educativos", concluía que los datos obtenidos destacaban el aumento de pobres e indigentes, $y$ "el incremento de la vulnerabilidad económica y social de los estratos medios". Véase, Lourdes Cárdenas, "A la extrema pobreza en AL, 50 millones más", La Jornada, Domingo 1o. de marzo de 1992. 
un brutal aceleramiento industrial, y luego por una brusca detención del mismo. Esto es, entre 1950 y 1980 América Latina primero rompió con un orden tradicional apostando todo a un crecimiento acelerado. Los resultados fueron: "explosión demográfica, urbanización salvaje, degradación ecológica". Sin embargo, "más brutal resulta la segunda fuente de desorden porque, una vez instalada en esta lógica de alto dinamismo, América se impacta sin la menor previsión contra el muro del estancamiento". En nuestro país los resultados muestran una sociedad terriblemente atomizada sufriendo una fuerte anomia. Además, es posible detectar en ella

desintegración e inestabilidad laboral, nula organización sindical, descomposición y ruptura de la cohesión familiar, exclusión política, escolaridad deficiente, religiosidad cuestionada, representaciones políticas rechazadas, urbanización salvaje, crisis desarrollista, etcétera. ${ }^{14}$

Lógicamente, bajo dichas condiciones el renglón educativo se convirtió en un sector no prioritario para la política económica del régimen. El recorte presupuestal y la reducción de los salarios fueron evidentes. En efecto, la cultura resulta no prioritaria para la elite gobernante no sólo porque implica una erogación, sino también porque en época de crisis encuentra gente sensible y receptiva a las críticas a la que explica las razones de su malestar. Por lo mismo no es accidental que la produc-

${ }^{14}$ Sergio Zermeño, "El regreso del líder: crisis, neoliberalismo y desorden", Revista Mexicana de Sociología, año 51, n 4, oct.-dic., 1989, p. 102 y 104. Según el autor, a la "crisis de progreso de los años ochenta hay que sumar "las acciones neoliberales del gobierno mexicano", para explicar y entender mejor la desorganización social que sufre nuestro país. Asimismo no deja de preguntarse si esta crisis de progreso no será de larga duración, y posiblemente abarque más de una década. Sin duda, su preocupación es justificada. Ahora, los diez años ya son quince, y el panorama no resulta nada promisorio. 
JAVIER MEZA

ción de ideas se busque aplastar o diluir mediante un mar de trivialidad y un desinterés promovido profusamente por todos los medios.

La esperanza y el deseo de transformar la educación se fueron convirtiendo en desaliento. No es fortuita la aparición en estos momentos de una lapidaria sentencia en todos los medios educativos y burocráticos: "Como ustedes simulan pagarme yo simularé trabajar." Y en efecto, así empezó a ser: el ausentismo, la escolaridad deficiente, el desaliento se convirtieron en algo cotidiano. La noble idea de convertir al estudiante en artífice de su educación en algunas mentes astutas e irresponsables empezó a ser entendida como la promoción de una educación anunciada elegantemente como autodidacta. Es decir, al papel de profesor lo convirtieron en un simple coordinador de las 'investigaciones' que el alumno debía desarrollar lejos de las aulas para que el profesor pudiera ausentarse. Para algunos, el profesor ni siquiera estaba obligado a sugerir bibliografía, pues también era obligación del alumno buscarla. Según esto, ahora, como 'coordinador', su deber solamente era acudir esporádicamente para vigilar las investigaciones trimestrales. ${ }^{15}$ Actitudes así contradicen totalmente los postulados originales, pues

Las funciones del docente se ubicarían teóricamente dentro de la corriente denominada 'autogestión pedagógica' (Georges Lapassade) y éstas se limitarían, en líneas generales, a la coordinación del grupo. Propondría inicialmente un modelo de trabajo y participaría en la medida en que el grupo se lo solicitara. Podría presentar temas, informar y orientar siempre y cuando hubiera una necesidad manifiesta por parte del grupo. También podría proponer alternativas de funcionamiento. El docente sería un analista, un técnico en organización y un educador

${ }^{15}$ En mi práctica he tenido que enfrentar hirientes comentarios de colegas de otras unidades que consideran al profesor de la UAM-X, debido a la degradación de la enseñanza modular, un simple 'toma-clases'. Si esto es cierto, ¿me pregunto si el problema de no preparar las clases sólo ocurre en nuestra universidad? 
que posee un conocimiento y una experiencia que debe transmitir. La participación de docentes y alumnos se debía dar en un proceso de enseñanza-aprendizaje en que ambas partes fuesen copartícipes, asumiendo una responsabilidad individual y colectiva. $^{16}$

Como vemos, el contrato requiere dos partes, y la exigencia fundamental es un excelente profesor, pero también un excelente alumno que demanda, exige, necesita, disiente con objeto de causa, y que por dignidad no está dispuesto a incurrir en complicidades complacientes de ningún tipo, pues lo único que realmente desea es aprender. ¿Qué ocurre con un profesor irresponsable ante excelentes alumnos? Y en otro sentido, ¿cuando el alumno busca al profesor complaciente $o$ 'barco' o 'trasatlántico' a qué ética obedece? ¿Qué podría hacer Jean Paul Sartre ante Chabelo? La buscada educación problematizadora, caracterizada por la acción y la reflexión, es imposible con la ausencia y el desinterés de docente y alumno.

\section{Un colapso ideológico}

Pero los problemas no solamente aparecieron por cuestiones salariales. Como si todo lo anterior no hubiese sido suficiente, a nivel educativo todavía faltaba recibir un impacto terrible. La caída del régimen burocrático-totalitario de la URSS trajo consigo la moda de hablar de la muerte de las ideologías, del fin de la historia, del fracaso de la Razón. La llamada postmodernidad con su cinismo, desaliento e imbecilidad se abrió paso. Según el filósofo, como el anhelado y esperado orden mundial de la libertad nunca llegó, las categorías fundamentales en que se basaba dicha esperanza, como Progreso, Historia, Razón, Revolución y Democracia se vaciaron de todo contenido. Y dentro de

${ }^{16}$ ler. congreso sobre las bases conceptuales de la Universidad Autónoma..., op. cit., t. 2, p. 59. 
JAVIER MEZA

este panorama lo más grave ha sido el olvido de algo fundamental, es decir, la necesidad de

cuestionar los grandes discursos históricos y al mismo tiempo cuestionar con ellos el poder uniformador y coercitivo de los sistemas globales de dominación que precisamente han legitimado estos discursos. Pero la mentalidad postmoderna de la década de los ochenta no realizó precisamente esta prometida crítica. Se limitó a exponer la doctrina nihilista del final de los grandes discursos filosóficos. Postuló una muerte. Defendió existencialísticamente la metafísica decadente de la muerte. Celebró con complacencia más o menos irresponsable la liquidación de las esperanzas históricas de un reciente pasado. Para embarcarse bajo el signo de un arcaico pesimismo existencial por los rumbos apocalípticos del fin de la historia. ${ }^{17}$

Pero además, la desaparición de toda crítica junto con el deseo de emancipación, de una $u$ otra manera ha permitido el reforzamiento de "racionales sistemas tecno-económicos de producción" de corte totalitario, que empujan cada vez más a la miseria y al abandono a masas inermes. En nombre de la productividad por la productividad y del mercado libre los derechos sociales hace tiempo conquistados por los pueblos son pisoteados y arrebatados. Sin duda, para los amos del mundo se trata de regresar a las condiciones de un capitalismo salvaje parecido al que existió en Inglaterra alrededor de 1820, pero con la novedad de querer implantarlo a nivel mundial. Esto es, se busca:

restaurar una situación en la que los pobres, o sea la gran mayoría, tienen que ganar sus derechos en el mercado laboral. Pero ahora tiene que ser un mercado laboral flexible, sin sindicatos, sin pensiones, sin contratos colectivos; no puede haber lo que el Banco Mundial llama 'rigidez'. Y sólo se obtendrá lo

${ }^{17}$ Eduardo Subirats, Los malos días pasarán, op. cit., p. 12-3. 
REPENSAR LA UNIVERSIDAD

que uno consiga siendo un ser humano que intenta venderse en el mercado laboral. ${ }^{18}$

En alguna ocasión Max Horkheimer y Theodor Adorno reflexionando acerca del totalitarismo soviético y su apología a ultranza del trabajo, concluían: "Si Marx se sale con la suya la tierra se convertirá en un enorme taller." En efecto, ciertas corrientes socialistas jamás se opusieron a la concepción del 'cuerpo productivo' bendecida por el capitalismo, y asumieron loar y defender las glorias de la producción. Precisamente en 1825 Stendhal rechazó burlonamente las pretensiones de los discípulos socialistas de Saint-Simon que, siguiendo a su maestro, en el periódico Le Producteur proponían: "La capacidad industrial es la que debe estar en primera línea, la que debe juzgar el valor de todas las demás capacidades y hacerlas trabajar en todas para su mayor ventaja." Para el escritor, esto más que ridículo resultaba estúpido. A su juicio, todos los industriales

han hecho el bien público como consecuencia de su bien particular. Son unas buenas y honradas gentes muy honorables para mí y a las que con gusto vería nombrar alcaldes o diputados, pues el temor a las quiebras les ha hecho adquirir ciertos hábitos de desconfianza, $\mathrm{y}$, además, saben contar. Pero busco en vano lo admirable en su conducta. ¿Por qué habría de admirarlos más que al médico, al abogado o al arquitecto?

Y después de muchas otras ironías, Stendhal concluía que mientras en la sociedad ocurrían un sinnúmero de importantes acontecimientos: "Un honorable ciudadano ha traído cabras del Tibet." 19 Hoy, el neoliberalismo habla mucho de calidad total y excelencia, pero a nivel mundial

${ }^{18}$ Ver David Brooks y Jim Cason, "Entrevista con Noam Chomsky", La Jornada, 6, 7 y 8 de noviembre de 1994.

${ }^{19}$ Henri Beyle, "Stendhal", De un nuevo complot contra los industriales, en Obras Completas, 1964, México, Aguilar, t. III, p. 773-80. 
JAVIER MEZA

ni gobernantes, ni banqueros, ni industriales ni comerciantes la demuestran. Por lo visto, todo es una impostura para explotar mejor.

Teóricamente, los trabajadores de las ideas serían quienes mejor podrían defenderse y enfrentar organizadamente (por supuesto que con muchas ideas) la amenazante realidad arriba descrita. Pero hasta el momento ellos han sido los más rápidamente desarticulados, sometidos, silenciados y muchos incluso comprados. Al bajo salario nominal el régimen respondió con estímulos y becas, y desde ese momento, sin resistencias ni cuestionamientos, el mayor porcentaje del ingreso se convirtió en un problema de contratación temporal e individual sujeta a la productividad. Si bien, a simple vista, puede ser justo y lógico que quien más trabaja perciba más, el asunto no es tan sencillo. En un primer plano aparece el problema de los parámetros que sirven para evaluar el trabajo intelectual. Éstos no siempre son justos: el capricho del que evalúa también se ejerce. Además, quien pretende escribir sabe perfectamente cómo en ocasiones lograr plasmar una idea constituye un gran esfuerzo, pero para el que la califica quizá sólo amerita unos cuantos puntos. Por otra parte, en una realidad corrupta la evaluación sobre la calidad del trabajo realizado puede estar sujeta a la influencia, a la simpatía o a la 'personalidad' de quien es evaluado. No es lo mismo evaluar a un exrector o a un profesor con influencias que a un simple profesor. Somos humanos y las comisiones evaluadoras no son inmunes a las presiones e intereses de los grupos de presión que siempre existen. En algunas divisiones las comisiones son corruptas y ejercen su poder con prepotencia y cinismo. Además, saber que la felicidad o la frustración del otro está en nuestras manos produce un placer morboso que puede convertirse en incontrolable. Desde que se promovió la cultura de la evaluación surgió la pregunta: ¿quién se encarga de evaluar a los evaluadores? La pregunta tiene sentido. Asimismo, hay que considerar la presión que sufre un profesor que desea renovar sus becas y estímulos y sabe que el tiempo para hacerlo se le termina. En la UAM actualmente se han realizado ciertas reformas al respecto; sin embargo, sólo singularizan todavía más las circunstancias de cada sujeto, y mientras más distintas sean más difícil será organi- 
zarse y buscar colectivamente una solución. A mediano y largo plazo se vislumbran dos serios problemas. Uno tiene que ver con la calidad de lo producido. Sin duda, la política de la zanahoria permitirá llenar aún más el mundo de basura. ${ }^{20} \mathrm{El}$ otro se refiere a la jubilación. Tanto las becas como los estímulos no forman parte del salario base, y ¿cuál va a ser la alternativa para un profesor que los años le obligan a retirarse?, ¿conformarse con su miserable salario?

Paralela a la política de los estímulos y becas la universidad pública igualmente enfrentó una fuerte campaña de desprestigio cuyo objetivo era, sin duda, justificar ante la opinión las duras políticas gubernamentales hacia ella y fortalecer el negocio de las universidades privadas que, en su mayoría, son efectivas sobre todo para obtener prestigio social. ${ }^{21}$ Dicha campaña, en muchos sentidos olvidó que cuando una sociedad sufre una crisis ésta se manifiesta en todos los niveles. Un fuerte problema al que nos enfrentamos actualmente es que nunca hemos sido un pueblo preocupado por el saber. Independientemente del es-

${ }^{20}$ Este sistema también puede repercutir negativamente en la calidad de las lecturas de los módulos. Utilizar en ellos el trabajo de los profesores es bueno, permite que los alumnos lo conozcan y además son puntos para él. Sin embargo, el problema para el alumno surge cuando por estudiar un trabajo de mediana calidad se queda sin conocer los clásicos. No hay que olvidar que siempre existen fuentes primarias y fuentes secundarias; la mediana calidad no debe estar nunca en primer término.

${ }^{21}$ Al respecto, creo que la siguiente opinión sigue siendo válida: "Las Universidades privadas, pues, por uno u otro motivo, nunca pueden responder a las exigencias superiores de la cultura y de su creación progresiva, porque no tienen como fin y norma la realización de un servicio público; ni mucho menos pueden responder al principio de la libertad académica, esencial para una sociedad democrática; y sólo por ironía o por deformación de los conceptos pueden llamarse libres. La libertad académica es incompatible con la exigencia de conformismo; necesita el diálogo y el choque de las opiniones opuestas de donde puede encenderse la chispa de nuevas intuiciones y nuevos descubrimientos", Rodolfo Mondolfo, Universidad: pasado y presente, op. cit., p. 68. 
JAVIER MEZA

trato social, el analfabeto funcional está en todas partes: tanto en las universidades públicas como en las privadas. Saber leer y escribir en ningún momento es garantía de que ese saber se utilice. Esta situación viene reforzada por la televisión y el video-game. Gracias a ellos la experiencia individual, la imaginación, el conocimiento y 'la confrontación emocional con lo real' se sustituye con 'la realidad como performance'. Hoy se percibe una crisis del sujeto, el cual se encuentra sin deseos de obtener autonomía y libertad, y de buscar "la experiencia individual del conocimiento de la realidad". ${ }^{22}$ El descerebramiento (término caro a Alfred Jarry) de los individuos no es una ficción, es una realidad. ¡La televisión es nuestro cerebro!

\section{Universidad y contexto}

¿Cómo entender a la UAM-X sin antes considerar todo lo anterior? ¡Imposible!, pues es reflejo de un entorno, dado que la crisis universitaria en particular y la de la educación en general es un problema de todos. ¡Es inútil cerrar los ojos y pensar que todo marcha bien! El optimismo corresponde al poder, al estudiante la crítica y la denuncia, aun cuando resulte amarga y ofensiva y se considere despectivamente como pesimista. ¿Se trata de fingir amnesia y cantar apologías o de plantear y resolver problemas? Después de todo no existen sistemas

${ }^{22}$ La situación no es nada halagüeña, y es claro que ningún gobierno tomará la iniciativa para hacer algo al respecto si no existe la presión de la sociedad civil. Las siguientes palabras no exageran: "Pantallas nos informan y nos forman, pantallas nos ponen en contacto con el mundo, pantallas nos vigilan, pantallas expresan nuestros deseos y extienden nuestros sentidos, pantallas registran, reproducen, producen, crean, pantallas descubren nuestra conciencia y nuestro cuerpo, pantallas dan cuenta de nuestra felicidad y nuestra enfermedad...Es como si todo, desde nuestros sueños hasta las grandes decisiones que afectan al porvenir de la humanidad se hubiera convertido en un prodigioso y monumental efecto de pantalla", Eduardo Subirats, op. cit., p. 18-9, 35 . 
educativos superiores e inferiores: sólo existen la voluntad y el deseo. Como antes señalamos, un buen profesor con pésimos alumnos desperdicia su capacidad; buenos alumnos con un mal profesor no aprenden nada. Según Maquiavelo si cualquier república tuviese que elegir entre tener hombres virtuosos o instituciones fundadas en excelentes principios, siempre debería buscar lo primero. Y tenía razón. El mejor sistema de enseñanza, innovador, revolucionario, con recursos, etcétera, no sirve para nada si sus profesores y alumnos no tienen pasión y voluntad por aprender. Es decir, deseos de resistir a la estupidez que socialmente nos abruma. Los principales fundamentos de la enseñanza modular, como la participación reflexiva en el aula y la investigación, no se cumplen cuando los alumnos carecen de la elemental disciplina para leer y escribir. Además ¿cómo discutir o exponer un tema con un alumno del Tronco Divisional de Sociales cuando egresó de la preparatoria careciendo de referentes básicos $?^{23}$ Lo mismo ocurre con la investigación: ¿cómo realizarla sin leer? Recortar citas de diversos autores y pegarlas unas con otras recuerda al criminal método de enseñanza implantado en las escuelas primarias consistente en 'aprender' mecanografiando literalmente el texto colocado al reverso de las estampas monográficas. ${ }^{24}$ Por otro lado, los objetivos del trabajo en equipo tampoco se cumplen cuando se convierte en una estrategia para trabajar y aprender menos. No es lo mismo leer individualmente un libro completo a leer solamente un capítulo y esperar a que el resto

${ }^{23}$ Quizá sería exigir demasiado que por lo menos supiesen quién es, por ejemplo, Franz Kafka, Shakespeare, o explicasen el mito de Prometeo. Pero el problema es muy serio cuando uno se encuentra con que ni siquiera saben quién es Juan Rulfo.

${ }^{24} \mathrm{Al}$ respecto resultan sumamente ilustrativos dos chistes inventados por los alumnos a principios de los años noventa: "La UAM-X es la única cafetería que cuenta con una universidad integrada", y "para aprobar en la UAM-X sólo es necesario saber escribir a máquina, fumar y tomar café". Para el espíritu serio el sarcasmo es mentira, pero no hay que olvidar que a nuestra sociedad desde hace muchos años sólo se le permite manifestarse mediante la venganza de la burla amarga. 


\section{JAVIER MEZA}

del equipo lea los restantes para luego en la biblioteca discutir a gritos y colectivamente lo que no se leyó, olvidando, por supuesto, que las bibliotecas no son para platicar. Además, es indudable, una es la investigación modular y otra, digamos, la investigación científica. La primera es un proceso didáctico, cuyo objeto es la transmisión de conocimiento; la segunda pretende descubrir algo ignorado. Es decir: "investigar para aprender mejor una disciplina es totalmente distinto de investigar para crear un conocimiento original en la disciplina". Por ignorancia, muchas veces se comete la torpeza de "inducir en los estudiantes la idea de que la investigación cientifica es algo fácil y cómodamente accesible, cuando sabemos bien que simplemente el estudiar la bibliografía sobre cualquier tema específico insume un tiempo mayor que todo el disponible en un año curricular". ${ }^{25}$ La torpeza no tiene nombre cuando se pretende pasar por ciencia el trabajo de 'tijera y engrudo' que antes mencionamos.

Pero es obvio, los adolescentes no tienen la culpa del mundo de impostura legado por los adultos. En nuestra sociedad el conocimiento, el esfuerzo, el trabajo, la responsabilidad, resultan prácticamente patológicos. La norma y el ejemplo imperante brindado por la mayoría de nuestros hombres públicos es el cinismo y el menor esfuerzo. Todavía somos una sociedad barroca apuntalada por la simulación, la ficción, la apariencia, es decir, por la mentira aceitada con la corrupción. A menudo una crisis se ve como una decadencia. No creo en eso. Nosotros no hemos podido ser porque nunca hemos dejado de ser: antes no fue mejor. Las crisis también son curación. Cuando, luego de mirar el entorno, un adolescente pregunta ‘ ¿para qué estudiar?' hasta cierto punto tiene razón: el futuro ahora no es halagador. ${ }^{26}$ De los 80 millo-

${ }^{25}$ ler. congreso sobre las bases conceptuales de la Universidad Autónoma..., op. cit., t. 1, p. $42 \mathrm{~s}$.

${ }^{26}$ Esperemos que los cálculos mientan: "Se proyecta que para el año 2010 , la población de México estará cerca de los 200 millones. Debido al pasado crecimiento, México es un país de jóvenes. Las estimaciones de las Naciones Unidas indican que en 1985, 42.2\% de los mexicanos tenían menos de 15 años, lo que significa que cada año, de 700 a 800 mil jóvenes de ambos 
nes de mexicanos que somos, aproximadamente 50 millones tienen menos de 24 años, y su realidad es bastante sórdida:

Sin esperanza para el futuro, porque la crisis económica prolifera hasta convertirse en apatía, sin un respaldo en la comunidad, porque hasta el apoyo de la familia y de la banda se difuminan, sin adversario nítido o principio ético de identidad, la juventud mexicana tiende a una situación de descomposición, de inorganicidad, de retraimiento que la conduce, en el extremo, al refugio individual, a la introversión, a la crisis personal, a la destrucción de las capacidades del sujeto para la integración social, a la indiferencia y al olvido, situación no lejana del 'conformismo delincuencial' ayudada por drogas y todo tipo de productos tóxicos. ${ }^{27}$

\section{Universidad para la sociedad civil}

Las prácticas económicas neoliberales de los gobiernos de los últimos años, como antes señalamos, han buscado el desprestigio de las universidades públicas al grado de considerarlas como inútiles, con el fin de recortar aún más los subsidios y convertirlas en empresas autofinanciables en nombre de la libertad económica. No es gratuito que los hombres de empresa y los mercaderes, autonombrados voceros de la sociedad, como siempre demagógicamente, externen públicamente sus

sexos ingresan al mercado de trabajo. Únicamente para reducir el índice de desempleo abierto del presente nivel de 14 a 6\%, México tendrá que generar cerca de un millón de empleos por año hasta fines de este siglo." Ver Richard A. Nuccio, y Angelina M. Ornelas con la colaboración de Iván Restrepo, "El medio ambiente en México: seguridad para el futuro", En busca de la seguridad perdida. Aproximaciones a la seguridad nacional mexicana, Sergio Aguayo Quezada y Bruce Michel Bagley (compiladores), 1990, México, Siglo XXI, p. 264-92.

${ }^{27}$ Sergio Zermeño, ibid. 
JAVIER MEZA

pretensiones de participar en la elaboración de los planes de estudio de los centros superiores. Si la imbecilidad triunfa y las universidades públicas se convierten en un gran bazar, los profesores debemos empezar a preocuparnos por enseñar únicamente cómo obtener la máxima ganancia de la producción y de la venta de productos. Estas pretensiones traicionan abiertamente a la gran mayoría productora de la riqueza, y por lo mismo, sufragante no sólo de los gastos de la educación: la sociedad. La sociedad (que mayoritariamente no está integrada por politicastros ambiciosos y hombres de empresa partidarios de la máxima irresponsable de 'o bien vendido o bien podrido'), como bien dice Hutchins, está más urgida de ciudadanos responsables formados por una educación que permita a la gente "evaluar y resistir las malas artes de quienes se dedican a despojarla del poder político que la educación debía proporcionarle", y que asimismo evite "convertirla en víctima propiciatoria de la publicidad y de la propaganda". ${ }^{28}$ Por lo tanto, el objetivo fundamental de la educación debe buscar cimentar en los individuos principalmente un "crecimiento moral, intelectual, estético y espiritual". Tal anhelo, por supuesto, en ningún momento lo podrían lograr los políticos ni los industriales, sino solamente los profesores responsables ante la sociedad civil y los estudiantes deseosos de saber, tomando en cuenta siempre que:

Cualquiera haya sido la situación en épocas anteriores o en otros tipos de sociedad, la sabiduría que necesita una comunidad democrática es la sabiduría de toda la población. Cuando unos pocos dirigen el Estado, puede bastar con que ellos posean sabiduría; cuando todo el pueblo es, en última instancia, el

${ }^{28}$ Véase de Robert M. Hutchins, La universidad de utopia, 1959, Buenos Aires, EUDEBA, p. 18-9. Desde mi punto de vista, en momentos de crisis lo más recomendable es regresar a los autores clásicos, y éste lo es. Además, cuando uno lee algunos de los planteamientos educativos de la UAM-X, (independientemente de su cristalización) el libro de Hutchins no deja de guiñar el ojo. 
que gobierna, es necesario que todo el pueblo la posea. Entonces el hombre de la línea de montaje, el campesino, el abogado, el médico, el ingeniero o el ama de casa, deben tener preparada su contribución al fondo común de sabiduría, pues, aunque una democracia debe tener líderes, es el pueblo el que los elige y los dirige. ${ }^{29}$

Como he señalado, los sistemas educativos y las ideas al respecto son muy importantes, pero más lo es la voluntad y el deseo: sin ellos no existe nada. Para una universidad es importante conservar, transmitir e innovar. Pero en situaciones graves quizá lo más importante sea lo primero pues en la medida en que mínimamente lo logra se constituye en un fuerte puntal para la sociedad sedienta de sobrevivir. Entonces puede ser, ni más ni menos, su memoria viva. Hoy, la UAM-X debe rescatar, conservar y transmitir las características de una de las principales definiciones de interdisciplinaridad que la inspiraron, y que sin duda es aplicable a toda nuestra cotidianidad siempre y cuando se desee apostar todo para obtener: curiosidad, receptividad, imaginación, aventura, preocupación por el entorno y deseos de saber. ${ }^{30}$

${ }^{29}$ Op. cit., p. 24.

${ }^{30}$ Véase nota 1. 